\title{
Internacionalización
}

\section{y globalización del arte: la necesidad de traducir en contextos expositivos}

\author{
Modesta Di PaOla*
}

INTERNACIONALIZACIÓN Y GLOBALIZACIÓN DEL ARTE:

LA NECESIDAD DE TRADUCIR EN CONTEXTOS EXPOSITIVOS

\section{Resumen}

El fenómeno de la globalización del arte ha eliminado las fronteras territoriales que caracterizaban los distintos mapas culturales y estéticos de cada país y confundido los márgenes propios de la creación artística, sobre todo cuando esta se basa en la utilización de los medios tecnológicos y en la interconexión entre lenguajes, lenguas y culturas. La preocupación acerca de la desaparición material de la obra a favor de sus elementos conceptuales, así como del fenómeno de espectacularización y comercialización de la producción artística por parte de las instituciones del arte, comporta una reflexión acerca de las dinámicas políticas internacionales y de sus efectos en la identidad del arte local y nacional. El movimiento de los artistas, que en muchos casos tienen que modificar la esencia estructural de sus obras para que un público heterogéneo pueda interpretarlas, vuelve siempre más complicada la interpretación del mensaje cultural inserto en sus trabajos. En este contexto, la traducción se vuelve una necesidad.

\section{INTERNATIONALIZATION AND GLOBALIZATION OF ART: \\ Translation as a Necessity in Exhibition Contexts}

\section{Abstract}

The globalization of art has eliminated the territorial borders that once characterized the cultural and aesthetic maps of different countries, and has blurred the boundaries of artistic creation, especially that based on the use of technology and the interconnections between languages and cultures. General concern about the disappearance of physical artworks in favour of their conceptual elements, and about the spectacularization and marketing of artistic product by art institutions, entails a reflection on international political dynamics and their effects on local and national artistic identities. The movement of artists in an interconnected world leads them to, in many cases, modify the structural essence of their artistic work in order to offer more easily understood cultural and linguistic messages. In this context, translation is a necessity.

Di PAOLA, M., «Internacionalización y globalización del arte: la necesidad de traducir en contextos expositivos», Acta/Artis. Estudis d'Art Modern, 4-5, 2016-2017, págs. 99-107

PALABRAS ClaVE: Globalización, arte mundial, exposición, traducción, diáspora

KeYwoRDs: Globalization, world art, exhibition, translation, diaspora

\footnotetext{
* Este trabajo se enmarca en el proyecto de investigación CCAV/ART II «Cartografía crítica del arte y la visualidad en la Era Global: nuevas metodologías, conceptos y enfoques analíticos» (HAR201343122-P), financiado por el Ministerio de Economía y Competitividad.
} 
En Ciudad pánico. El afuera comienza aqui ${ }^{1}$ Paul Virilio se enfrenta a las problemáticas acerca de la transformación radical de lo político, de lo social y de lo humano en la época de la información de masas. Aquí, el filósofo francés nos lleva al punto más álgido de su pensamiento sibilino describiendo el fenómeno de la creación sin creación que se concreta en el acto de sustracción, desmaterialización e in-presencia de la obra de arte. En términos políticos esta in-presencia correspondería por similitud a la «des-territorialización aero-orbital» de la era de la globalización. Así, la lógica de la creación de una presencia, lo que era la obra de arte en su materialidad, se ha sustituido en nuestra contemporaneidad por la lógica de la desaparición presente tanto en el ámbito artístico como en el terreno de la geopolítica. Según Virilio, el criterio del «acontecimiento» narrado, presentado y representado ha dado paso a la lógica del «accidente», una práctica muy contemporánea que produce un evento sensacionalista y espectacular en el que desaparecen las formas tradicionales de presentación y preservación: crear el «accidente» es lo que caracteriza la normalidad cotidiana tanto en el arte como en la política.

Esa clase de expresionismo es buscada hoy en día universalmente, tanto por los «terroristas» como por los «artistas» y todos los activistas contemporáneos de la era de la globalización planetaria. ${ }^{2}$

A la política-espectáculo producida por el fenómeno de la globalización denunciada por Virilio corresponde la crítica al sistema del arte en la era de internacionalización neoliberal y económica impulsada por los países occidentales, igualmente espectacular y propagandista:

qué queda de la noción de obra cuando incluso la de «obra maestra» ha desaparecido hace tiempo? ¿Qué queda, paralelamente, del autor, del creador, desde que Dios ha muerto, según la lógica también promocional de Friedrich Nietzsche? ${ }^{3}$

La preocupación acerca de la desaparición de la obra se comparte en las ideas de algunos teóricos y curadores que investigan los efectos de la economía y de las políticas de producción y visualización del arte en la era global. «Global art and the Museum», por ejemplo, ha sido el tema de una investigación internacional y de un proyecto curatorial desarrollados durante cinco años y dirigidos por Hans Belting, Andrea Buddensieg y Peter Weibel desde el Center for Art and Media (ZKM), Karlsruhe. La finalidad del proyecto ha sido la de documentar los confines de la denominada art world (arte mundial) a partir del análisis de las transformaciones del arte contemporáneo provocadas por la globalización. En muchos países —no solo occidentales-la producción artística se ha vuelto un proyecto económico que incluye estrategias muy precisas por parte de las grandes instituciones del arte. Según los teóricos involucrados en el proyecto, el arte se ha convertido en un programa sociopolítico impulsado por ideologías de la identidad, por la autodeterminación de grupos y comunidades y por los cambios sociales a nivel global. Este largo proyecto culminó con la publicación del libro The Global Contemporary: The Rise of New Art Worlds after 1989, ${ }^{4}$ que recoge importantes artículos de Hans Belting, Peter Weibel, Parul Dave Mukherji, Terry Smith, etc., acerca de una new art world surgida en plena globalización.

El artículo de Smith, titulado «Contemporary Art: World Currents in Transition Beyond Globalization», parece parafrasear a Virilio cuando describe tres bloques conceptuales, o fenómenos, que dominan el mundo artístico contemporáneo: el remodernist, el retro-sensationalist y el spectacularist. La globalización artística, según Smith, encuentra su primer momento his-

1. VIrILIo, P., Ciudad pánico. El afuera comienza aquí. Traducción de Iair Kon. Buenos Aires: Libros del Zorzal, 2006.

2. Ibidem, pág. 37 .

3. Ibidem, pág. 38

4. Belting, H.; Buddensieg, A.; Weibel, P. (eds.), The Global Contemporary: The Rise of New Art Worlds after 1989, cat. exp., 17 de septiembre de 2011 - 5 de febrero de 2012, ZKM, Karlsruhe. Cambridge, MA: MIT Press, 2013. 
tórico en la mayoría de los movimientos artísticos nacidos entre Europa y América en la década de los cincuenta y de los sesenta, como el pop, el minimal, el conceptual, el process y el land art. Movimientos todos ellos que entre los años setenta y ochenta se volvieron un tema de discusión y de análisis también fuera de los confines occidentales. En estos mismos años, además, las teorías posestructuralistas acompañaron el surgimiento de las prácticas artísticas posmodernas, reforzando notablemente la expansión a nivel mundial de las producciones locales y nacionales. Según Smith, sin embargo, la tendencia económica de comercializar las obras de arte periféricas en auge durante la década de los noventa ha contribuido a la creación de etiquetas como world art, global arty geoaesthetics art para describir el fenómeno general de «mundializar» el arte:

Since then, contemporary art everywhere has engaged more and more with spectacle culture - with image-saturated commerce, globalized lifestyle, and social media - and with anxieties caused by political volatility and climate change. ${ }^{5}$

Desde entonces, los mayores museos del mundo, poniéndose como centros de atracción de la cultura del espectáculo, han promovido la concepción de un arte global que se caracteriza por dos fenómenos principales: el primero, de carácter económico y político, ha empujado la tendencia de comercializar el arte en un mundo siempre más conectado entre Occidente y Oriente, Norte y Sur; el segundo ha sido determinado por las grandes instituciones del arte que tienen la voluntad de espectacularizar la actividad artística volviéndola un tema de interés económico y, consecuentemente, de desmaterializarla de su contenido cultural original.

$\mathrm{El}$ «movimiento» reiterado de bienes y culturas por todo el planeta ha motivado algunas ideas catastróficas acerca del fenómeno de la contemporánea globalización artística, como lo demuestran los movimientos de proliferación de aptitudes antiglobalizadoras, de resistencias localistas, y el cosmopolitismo crítico, surgidos sobre todo en los contextos territoriales y culturales pertenecientes a las excolonias. Según Smith, estas actitudes han empezado a caracterizar el circuito de las bienales y de las exposiciones internacionales de arte itinerante. Testimonio de ello son, por un lado, los discursos teóricos y las piezas artísticas de clara tendencia antiimperialista que los curadores eligen a la hora de representar la identidad o la imagery de lo nacional y de lo local dentro de los circuitos nacionales e internacionales, ${ }^{6} \mathrm{y}$, por otro lado, los movimientos de resistencia - motivados en la mayoría de los casos por la actual condición disyuntiva entre las economías mundiales predominantes- que han puesto en stand by la ola hegemónica de la globalización como fenómeno mundial, fomentando actitudes proteccionistas que han priorizado la exhibición de los productos locales y regionales. ${ }^{7}$

Sin embargo, pese a la tentativa de visualizar, promover y proteger las artes nacionales de los efectos de la globalización cultural, económica y política, la tendencia general que define teóricamente y que caracteriza formalmente la producción artística actual, es la naturaleza híbrida y compuesta del arte contemporáneo. El fenómeno de la internalización del arte no solo ha eliminado las fronteras territoriales que caracterizaban los distintos mapas culturales y estéticos de cada país, sino que ha confundido los márgenes propios de la creación artística, sobre todo cuando esta se basa en la utilización de los medios tecnológicos y en la interconexión entre

5. Sмiтh, T., «Contemporary Art: World Currents in Transition Beyond Globalization», en Belting, H.; BudDEnsieg, A.; WeIBEL, P. (eds.), The Global Contemporary..., pág. 187. Según Smith, la diversidad de las prácticas artísticas contemporáneas, más que estar ubicadas dentro de algunas categorías que las conforman bajo modelos hegemónicos, como global art, world art, o geoaesthetics, tendrían que ser reconocidas basándose en sus peculiaridades distintivas y en sus específicos niveles geográficos — como lo local, lo regional y lo internacional (worldy) —. Smith, además, desplaza el objeto de la crítica hacia una interpretación ontológica del arte internacional insertándolo dentro del concepto de ser-en-el-mundo.

6. Ibidem, pág. 188.

7. Idem. 
lenguajes y lenguas. Además, la movilidad contemporánea ha propiciado una oferta de trabajo para muchos artistas - no solo de las periferias - y una posibilidad cotidiana de hibridar ideas, conceptos, lenguas y soportes: el libre movimiento entre varios continentes, exponiendo en museos, instituciones culturales, sitios de Internet, e incluso la celebración de cursos, seminarios o talleres en los lugares más remotos del mundo, caracterizan al fenómeno contemporáneo del «nomadismo transcultural como misión». En todos estos traspasos es común que los artistas reformulen sus obras para que se adapten conceptual y lingüísticamente a las culturas de acogida, que alteren sus mensajes para convertir sus piezas en material narrativo de fácil lectura para que el otro cultural y lingüísticamente diferente pueda comprenderlas. De esta manera, junto con el desplazamiento de los artistas, las obras de arte viajan entre instituciones y en las exposiciones internacionales itinerantes fomentando el surgimiento de la «hibridación de la esencia estructural de la obra de arte». En este contexto, la tentativa de exponer un arte nacional, con sus propias peculiaridades culturales e identitarias, se derrumba delante de un objeto artístico que se ha hibridado debido al efecto «colonizador» de la globalización artística, determinando una transformación no solo en la identidad estructural de la pieza, sino también en su image y en su imagery, y más allá de los confines nacionales en la que se encuentra, es producida, presentada o interpretada. ${ }^{8}$

En un territorio caracterizado por la coexistencia de lenguajes artísticos, lenguas y culturas, la previsión de Smith según la cual «translation becomes the medium of necessity, of possibility and of hope $»^{9}$ se revela una declaración de fundamental importancia.

\section{INTERPRETAR NUEVOS CÓDIGOS CULTURALES}

La iconografía tradicional, como declara William Thomas Mitchell, se ha vuelto insuficiente desde que los fenómenos interartísticos y, sobre todo, el uso de las nuevas tecnologías, han empujado la tendencia a la repetición de lenguajes artísticos (técnicas y tecnologías) y códigos culturales. La repetición de códigos se hace mucho más patente desde que los artistas han empezado a dejar sus países y se han trasladado a otros de distintas habla y cultura. A la alteridad cultural de cada artista - muchas veces sujetos diaspóricos dentro de sus propios países en cuanto sujetos previamente colonizados pero también en los países de acogida en cuanto outsiders - corresponde una alteridad estilística y estética. Debido al hecho de que buena parte de la producción artística contemporánea ya no se diferencia por los estilos o lenguajes peculiares de una cultura, reconocer el origen y la singularidad de una obra — sobre todo en los contextos internacionales como las bienales- puede resultar complicado.

¿En qué consiste hoy día la singularidad de una obra de arte? ¿Cómo reconocerla e interpretarla? Las peculiaridades propias de cada artista han permitido la asignación, la autenticación y el reconocimiento de las obras también a muchos años de distancia, a veces siglos. Sin embargo, los signos característicos y singulares de cada artista ya no siguen las mismas reglas de un tiempo, e individuarlos de forma exacta necesita de algunas estrategias visuales muy claras y directas. No es una casualidad que hoy día las obras se acompañen con textos explicativos que ofrecen informaciones varias acerca de la obra y de su creador. El sistema del arte se ha vuelto por tanto mucho más eficiente no solo en términos de «explicación», sino también de tutela de la identidad. Galerías, museos e instituciones protegen la autoría de la pieza.

8. MrtcheLL, W.J.T., Iconology: Image, Text, Ideology. Chicago: University of Chicago Press, 1987.

9. Sмiтн, T., «Contemporary Art...», pág. 188. 
Los artistas mantienen sus nombres y sus peculiaridades gracias a una constante tutela de las obras, en términos de protección de derechos de exhibición, de producción de la imagen, de impresión, etc.

El objeto artístico desmaterializándose de su esencia fundamental, la forma pictórica - picture para usar la expresión de Mitchell-, se ha convertido en un artefacto poliédrico y complejo, a menudo de carácter intermedial, que se abre a conceptualizaciones de varios tipos, desde el ámbito humanístico a lo científico. Habiendo perdido cualquier tipo de referencia técnica, histórica, teórica o cultural, solo nos queda la posibilidad de interpretar directamente cada obra en su significado específico.

\section{UNA ÉTICA INTERCULTURAL EN LA RECEPCIÓN DE LAS OBRAS DE ARTE}

Los discursos sobre una ética intercultural que alienta el diálogo entre culturas «iguales» — culturas que quieren conocerse en lugar de abrumarse-motivan una investigación más profunda de las tendencias contemporáneas a la internacionalización del arte. Este fenómeno de extremo interés para historiadores del arte, críticos y curadores, ha suscitado algunos importantes problemas entre los que se encuentran la comprensión de la obra de arte, su traducción, su transmisión y su recepción. Hoy en día usar el término «comprensión» en su significado etimológico más profundo - cum prehendere: coger con, contener con el intelecto, abrazar con la mente las ideas, entender plenamente- parece ser más prolífero. Y en efecto, cuando las exposiciones de arte se mueven alrededor del mundo, cruzando las fronteras geopolíticas, comprender más que interpretar deviene un acto indispensable, aunque a veces complejo. Esta complejidad se debe a la dificultad de leer e interpretar las obras no solo desde un punto de vista formal -obras interlingüísticas o intermediales que usan diferentes medios y lenguajes-, sino también de contenido: el mensaje que la obra quiere expresar representa un complejo conjunto de valores culturales, morales y rituales que pertenecen a un artista (lectura intercultural). Sobre este propósito el filósofo norteamericano Arthur Danto afirmaba que la identidad de la obra depende de los contextos culturales en los que se encuentra y es interpretada. Nuestra visión viene condicionada por nuestra cultura de origen; así, una obra condensa, en un objeto aparentemente normal, pero oportunamente transfigurado, una cultura entera - la cultura del creador y la del receptor.

La historiadora del arte italiana Angela Vettese, apoyándose en las ideas de Danto, nos recuerda que en las Brillos Box de Andy Warhol se individúan una serie de referencias conceptuales comprensibles solo para quien comparte la cultura norteamericana. Sin embargo, «cosa accede se chi osserva quell'opera non conosce il sistema di riferimento?», ${ }^{10}$ es decir, el sistema de referencias comerciales y los valores culturales de esa nación. Este problema se ha fortalecido con el fenómeno de la globalización que desde los años ochenta ha empujado el arte visual a mantener una base teórica de tipo occidental y, sin embargo, lo ha llevado a desarrollar aspectos derivados de otras culturas." Así, las bienales, aunque tengan una estructura rígidamente occidental, acogen artistas de todo el mundo cuyas obras reflejan la cultura, los valores, los ritos y las tradiciones de sus propios países. En este contexto global ¿quién puede comprender las estratificaciones de sentido que conforman una obra de arte africano, indio o chino si no se conocen los fundamentos de culturas tan diferentes a las de Occidente? Además, hay que con-

10. Véase Vettese, A., Capire l'arte contemporanea. Turín: Umberto Allemandi, 2006, pág. 9.

11. Idem. 
siderar que las obras visuales se han alejado progresivamente de su elemento meramente visual y estético para concentrarse en los elementos mentales y conceptuales. En términos formales, la distancia del materialismo implica multiplicar los textos escritos como vehículos para introducir y explicar las obras. La escritura, la palabra escrita o verbal se ha vuelto un elemento formal y parte sustancial de las mismas. En todas las exposiciones individuales, colectivas, itinerantes, locales e internacionales se necesitan los textos escritos que traducen las informaciones acerca de la pieza y del artista. Son palabras que viajan con las obras de arte y que representan un potente medio de comunicación intercultural que relaciona diferentes públicos que poseen culturas y lenguas muy distintas. La identificación por parte del público es, de hecho, una parte fundamental del proceso de creación. Esta identificación se presenta solo si el mensaje puede llegar a su destino, ser traducido.

Desde un enfoque meramente lingüístico, Yuri Lotman consideraba una obra literaria una representación «individual»: «No puede existir en el texto artístico ningún tipo de sustituto adecuado en el plano de la expresión sin que se verifique una mutación en el plano del contenido». ${ }^{12}$ Del mismo modo, la traducción de las piezas artísticas muta inevitablemente parte de su contenido a la hora de trasladar el complejo sistema de referencias históricas, sociales e ideológicas que conforman las mismas. Siguiendo a Lotman, podríamos afirmar que la realidad histórico-cultural de la obra no se limita a la representación de la misma. La obra consiste en una image y en su relación con la realidad extratextual - la realidad, las normas literarias, la tradición, el sistema de las creencias- $-{ }^{13}$ Analizar un texto sin tener en cuenta la complejidad de las relaciones extratextuales sería como interpretar los elementos formales de una pintura y colocarla en un determinado tiempo histórico y social, ignorando los problemas dados por la percepción, por la interpretación de los elementos culturales e ideológicos, literarios y artísticos, por el código, la escritura y su traducción.

\section{EXPOSICIONES Y TRADUCCIÓN}

En contraposición al fenómeno que tiende a abrazar bajo una misma agenda internacional muchas manifestaciones de arte contemporáneo, Smith reconoce la producción artística que se crea a partir de prioridades nacionalistas e identitarias, especialmente las que derivan desde las culturas anteriormente colonizadas. La producción artística local o regional que se inserta dentro del circuito internacional del arte (bienales, exposiciones temporales itinerantes, etc.) es definida por Smith como «art of transnational transitionality». ${ }^{14}$ La condición de «transición transnacional» ha suscitado interés por parte de curadores, teóricos y artistas que han debatido cuestiones acerca de la globalización en términos de transferencias - de información, de bienes, de obras de arte, de ideas-, de traducción lingüística y cultural y de movilidad. En este contexto, la traducción es uno de los elementos privilegiados para la construcción de los discursos teóricos en la organización de exposiciones de carácter internacional.

Durante la primera década de 2000, el interés se ha concentrado sobre todo en la posibilidad de detectar los elementos de la traducción lingüística en los procesos de intercambio cultural y artístico entre países. En la Bienal de Venecia de 2007, por ejemplo, se presentaron

12. Lotman, J.M., «Il problema del testo», en NergaARD, S. (ed.), Teorie contemporanee della traduzione. Milán: Strumenti Bompiani, 1995, pág. 92

13. Ibidem, págs. 100-101.

14. Sмітн, T., «Contemporary Art...», pág. 189. 
algunos trabajos de traducción realizados por la Karl Marx School of English Language. Se trata de un grupo de filósofos, artistas y críticos de arte que residen en Moscú y que se ocupan de leer los libros de Marx confrontando las varias traducciones en ruso e inglés con los originales en lengua alemana. Este ejercicio lingüístico se abre a discusiones acerca de la importancia de los textos de Marx en la filosofía, en la política y en el arte. Seguramente la actitud hacia la traducción de textos filosófico-económicos en el ámbito artístico es una prioridad en un país como Rusia marcado por represiones políticas. La exposición Svoboda curada por Daria Khan en el Spazio Carbonesi de Bolonia, en 2001, representaba claramente esta postura. La palabra svoboda en ruso significa «libertad». Sin embargo, la palabra escrita en caracteres latinos pierde su sentido y se vuelve puro sonido, una combinación de letras en un diccionario. La pérdida del significado depende de varios factores. En primer lugar del proceso que lleva a la palabra a ser traducida en otro idioma; en segundo lugar por la posible «incomprensión» de la misma por parte de un público de habla no rusa; y para terminar, la desavenencia que el uso de la palabra tiene al no contar con un referente cultural que la proteja en su propia lengua. La palabra «libertad» (svoboda) ha perdido, de hecho, su significado social y artístico incluso en su mismo contexto lingüístico, debido a las restricciones políticas que han sufrido los artistas y los curadores. ${ }^{15}$

Es bastante sintomático que el concepto de traducción se asocie con exposiciones de carácter subversivo. Este es el caso de la exposición titulada Translated Acts. Performance and Body Art from East Asia. 1990-2001, curada por Yu Yeon Kim. ${ }^{16}$ Ya desde el título se subraya la voluntad de transmitir dos actos de traducción:

The first being the articulation of cultural identity, historical legacy, and inner expression into performance and the second the extension of the body and performative action into other mediums, such as photography, video and digital or networked space. ${ }^{17}$

En una era de globalización y multiculturalismo intensificado, los artistas asiáticos — principalmente de Japón, China, Corea y Taiwán- muestran una serie de performances en las que confluyen las problemáticas relacionadas con las identidades envueltas en los procesos de colonización y descolonización. Según Yu Yeon Kim, estos artistas se enfrentan a problemas de identidad frente a los flujos internacionales de ideas e influencias, fenómenos que quizá sean mucho más fuertes que en las comunidades diaspóricas de Europa o América. Los trabajos representados por los artistas japoneses, por ejemplo, se desarrollan por medio de la alta tecnología para traducir la naturaleza esquizofrénica de una cultura que se enfrenta al carácter dual de su sociedad, caracterizada por una realidad tan conformista y tradicional como fantástica e incluso fetichista, caso de la subcultura del manga y la animación. Alejandro González Iñárritu en Babel consiguió alcanzar una descripción bastante exacta de los personajes japoneses teniendo en mente la cultura fantasy. La chica muda representa en clave cinematográfica la transposición de un manga erótico, una perfecta traducción del fenómeno interartístico que domina las sociedades diaspóricas.

El arte coreano actual, por contra, parece reaccionar a una serie de actos represivos del gobierno que comenzaron en 1950 y terminaron con la masacre de Gwangju en mayo de 1980. En respuesta a esta represión, los artistas han empleado un lenguaje artístico parecido al realismo crítico político, definido hoy por el movimiento minjoong (people's art). Este término comprende no solo a la clase proletaria (en el sentido marxista-leninista) sino a toda una comunidad de estudiosos, teóricos y artistas: «in a period of total press censorship this form of realism served

15. Véase el artículo de la exposición publicado en la web de Exibart: http://tv.exibart.com/news/2008_lay_notizia_02. php?id_cat=78\&id_news=6709.

16. KIM, Y.Y., Translated Acts. Performance and Body Art from East Asia. 1990-2001. Berlín: The Haus der Kulturen der Welt, 2001.

17. Ibidem, pág. 13. 
both as a focus and expression of dissidence». ${ }^{18} \mathrm{El}$ mismo dilema se subraya en los trabajos realizados por los artistas de Taiwán que, a partir de un contexto cultural que se debate entre lo local y lo global, lo indígena y lo chino, han creado múltiples lenguajes y conceptos artísticos caracterizados por la memoria nacional. El arte deviene un instrumento para la crítica social y política, así como una profunda expresión de la condición humana. Las performances realizadas por los artistas chinos Wenda Gu y Xu Bing se caracterizan por el uso conceptual de la traducción y revelan los límites de una política represiva en relación con Occidente. Ambos artistas usan la caligrafía para jugar de modo provocativo con la semiótica occidental. Esto es evidente por ejemplo en la sorprendente pieza de Xu Bing realizada en un sótano de Pekín para expresar la relación entre el Este y el Oeste. Se trata de un claro ejemplo de transferencia de significados cuyos protagonistas son dos cerdos que copulan compulsivamente dentro de un gran corral lleno de libros de literatura china y occidental, y con fragmentos de los textos escritos sobre su piel con caracteres chinos y occidentales.

Uno de los elementos fundamentales de la obra de Wenda Gu es el uso de la caligrafía en las pinturas, en los diseños, en las instalaciones y en las performances. Retranslation \& Rewriting of Tang poetry \#1 es una performance en la que se realizaba un dibujo caligráfico gigante en tinta negra mezclada con cabellos humanos. El diseño se mostraba en realidad como una serie de ideogramas ilegibles, una crítica al sistema estético oriental, pero también a la sensibilidad occidental por lo exótico.

De mayor o menor importancia, las exposiciones que llevan en su propio título la palabra traducción han ido creciendo hasta la fecha y han aportado interesantes puntos de reflexión en las investigaciones sobre la interpretación de las obras. El concepto de traducción ha sido investigado no solo dentro de la esfera del lenguaje, sino también dentro del campo de la producción artística. En los últimos años, algunos curadores han querido abarcar las problemáticas relativas al acto de la traducción como metáfora y mediación en los procesos de presentación de las obras en contextos artísticos internacionales y en la recepción de las obras por parte de públicos culturales diferentes.

Algunos ejemplos son la exposición Übersetzung ist eine Form / Translation is a mode (2010), curada por Birgit Rinagl y Franz Thalmair, la cual tenía el propósito de individuar los puntos de contacto y las divergencias en el arte conceptual por medio de la traducción. Uno de los aspectos más interesantes de esta exposición es quizá la voluntad de investigar la manera en que se localizan las redes de comunicación internacional dentro de un mismo espacio apto para la presentación de obras que derivan de varios contextos geográficos y culturales, y consecuentemente las problemáticas que surgen a la hora de traducir y reinterpretar las obras por parte de un público más local. ${ }^{19}$

De mayor importancia es la exposición titulada The Spiral and the Square ${ }^{20}$ organizada en la Bonniers Konsthall en 2011, con el propósito de revelar las dinámicas que regulan la relación entre culturas y lenguajes. La exposición mostraba una serie de trabajos artísticos considerados por los curadores Daniela Castro y Jochen Volz «exercises in translatability». Quizá esta haya sido la primera tentativa curatorial de institucionalizar la traducción lingüística y cultural dentro del ámbito propiamente artístico. The Spiral and the Square tiene su punto de partida en la novela Avalovara (1973), del escritor brasileño Osman Lins, que se erige en eje de una cultura caracterizada por la propia traducción cultural. Desde Brasil el tema de la traducción se extiende hacia Noruega como inevitable encuentro entre culturas en un mundo globalizado. ${ }^{21}$

18. Ibidem, págs. 17-18.

19. La exposición Übersetzung ist eine Form / Translation is a mode se celebró en el Kunst Raum Niederoesterreich (9 de abril - 29 de mayo de 2010). http://www.kunstraum.net/en/programme/67-uebersetzung-ist-eine-form-translationis-a-mode.

20. Véase Arrhenius, S.; Bergh, M.; SJÖHOlM, C. (eds.), Translatability. Estocolmo: Albert Bonniers Förlag, 2011.

21. http://www.bonnierskonsthall.se/en/utstallning/spiralen-och-kvadraten-ovningar-i-oversattbarhet/. 
Dentro del panorama artístico global, mucha ha sido la importancia que se ha dado a la traducción desde varias perspectivas. En 2011 el museo alemán ZKM de Karlsruhe organizó la exposición The Global Contemporary. Art Worlds After 1989. Las temáticas principales de la exposición, recopiladas en el catálogo editado en 2013 por Hans Belting, Andrea Buddensieg y Peter Weibel, ${ }^{22}$ fueron, entre otras: «The Global Turn. 1989 and its Consequences», «Art history. The End of a Canon», o «Visual Worlds. Art and the Migration of Pictures». Dentro de esta última temática se presenta la sesión artística titulada Lost in Translation. New Biographies of artists, que recoge obras cuyo hilo común es la traducción cultural. En general, la producción artística presentada narra historias personales de artistas nómadas que tienen que adaptar su propia identidad, interpretando diferentes papeles en cada nuevo contexto en el que se convierten en artistas. Este tipo de self representation no entra dentro de la definición de retrato autobiográfico, sino que más bien se encaja en la tipología de la performance en la que los artistas interpretan un rol ficcional de sí mismos. Este mismo proceso se traduce en trabajos artísticos, como en el caso de Work in Progress - Personal Map de la artista Nezaket Ekici (Kirsehir), The End of Art de Tamy Ben-Tor, Drop the Monkey de Guy Ben-Ner, o la pieza titulada An artist who cannot speak English is no artist de Mladen Stilinović. Sin embargo, los mismos artistas pasan por diferentes fases del proceso de traducción: se trasladan, en términos de movimiento; se traducen, en términos lingüísticos y culturales; y se adaptan al nuevo contexto geográfico, institucional y a una audiencia culturalmente y lingüísticamente específica.

22. Belting, H.; Buddensieg, A.; Weibel, P. (eds.), The Global Contemporary... 